J Am Chem Soc. 2016 September 28; 138(38): 12502-12510. doi:10.1021/jacs.6b06663.

\title{
Chlorin-Based Nanoscale Metal-Organic Framework Systemically Rejects Colorectal Cancers via Synergistic Photodynamic Therapy and Checkpoint Blockade Immunotherapy
}

\author{
Kuangda Lut,§, Chunbai He ${ }^{\dagger} \S$, Nining Guo ${ }^{\dagger} \neq, \S$, Christina Chan ${ }^{\dagger}$, Kaiyuan $\mathrm{Ni}^{\dagger}$, Ralph R. \\ Weichselbaum ${ }^{\ddagger}$, and Wenbin Lin ${ }^{\dagger,}$, \\ tDepartment of Chemistry, The University of Chicago, 929 East 57th Street, Chicago, Illinois \\ 60637, United States
}

FDepartment of Radiation and Cellular Oncology and The Ludwig Center for Metastasis Research, The University of Chicago, Chicago, Illinois 60637, United States

\begin{abstract}
Photodynamic therapy (PDT) can destroy local tumors and minimize normal tissue damage, but is ineffective at eliminating metastases. Checkpoint blockade immunotherapy has enjoyed recent success in the clinic, but only elicits limited rates of systemic antitumor response for most cancers due to insufficient activation of the host immune system. Here we describe a treatment strategy that combines PDT by a new chlorin-based nanoscale metal-organic framework (nMOF), TBC$\mathrm{Hf}$, and a small-molecule immunotherapy agent that inhibits indoleamine 2,3-dioxygenase (IDO), encapsulated in the nMOF channels to induce systemic antitumor immunity. The synergistic combination therapy achieved effective local and distant tumor rejection in colorectal cancer models. We detected increased $\mathrm{T}$ cell infiltration in the tumor microenvironment after activation of the immune system with the combination of IDO inhibition by the small-molecule immunotherapy agent and immunogenic cell death induced by PDT. We also elucidated the underlying immunological mechanisms and revealed compensatory roles of neutrophils and B cells in presenting tumor-associated antigens to $\mathrm{T}$ cells in this combination therapy. We believe that nMOF-enabled PDT has the potential to significantly enhance checkpoint blockade cancer immunotherapy, affording clinical benefits for the treatment of many difficult-to-treat cancers.
\end{abstract}

\section{Graphical Abstract}

\footnotetext{
${ }^{*}$ Corresponding Author: wenbinlin@uchicago.edu.

$\S$ Author Contributions

K.L. and C.H. contributed equally.

Notes

The authors declare no competing financial interest.

Supporting Information

The Supporting Information is available free of charge on the ACS Publications website at DOI: 10.1021/jacs.6b06663.

Experimental details and supporting results for the synthesis and characterization of $\mathrm{H}_{4} \mathrm{TBC}$, TBC-Hf, and IDOi@TBC-Hf, cellular uptake, in vitro PDT efficacy, abscopal effect, and antitumor immunity, including Figures S1-S27 and Tables S1-S3 (PDF)
} 


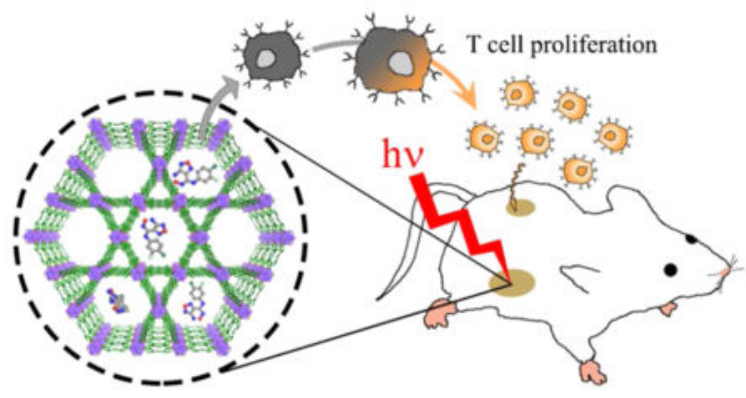

\section{INTRODUCTION}

Photodynamic therapy (PDT) combines nontoxic photosensitizers (PSs), light, and tissue oxygen to generate reactive oxygen species (ROS) such as ${ }^{1} \mathrm{O}_{2}$ to achieve local tumor control/rejection. ${ }^{1} \mathrm{PDT}$ is highly effective for the treatment of esophageal cancer and skin lesions but cannot completely eradicate deep-seated tumors due to shallow penetration of light through tissues. ${ }^{2}$ The localized light irradiation also renders PDT ineffective for treating systemically disseminated disease. Therefore, more efficient PSs and new treatment strategies are needed to enhance the efficacy of PDT in both eliminating local tumors and controlling distant metastases.

Significant efforts have been devoted to developing nano-particle-based PSs to enhance PDT in the past decade. ${ }^{3}$ We first reported the use of porphyrin- and chlorin-based nanoscale metal-organic frameworks (nMOFs) as efficient PSs for PDT of cancer. The stable framework and crystalline structure of nMOFs allow for high PS loadings, whereas the heavy metal cluster secondary building units (SBUs) facilitate intersystem crossing to enhance ${ }^{1} \mathrm{O}_{2}$ generation. ${ }^{4}$ We further demonstrated in a recent study that both apoptosis and immunogenic cell death (ICD) contribute to the anticancer efficacy of nMOF-enabled PDT. $^{4 \mathrm{~b}}$ The acute inflammatory response of PDT can alter the immunosuppressive microenvironment of the local tumor to prime the host immune system. ${ }^{5}$ We hypothesized that the porous nMOF structure could be leveraged to accentuate immune response by delivering small-molecule immunostimulatory agents in the open channels, combining PDT and immunotherapy to both eradicate local, treated tumors and reject distant, untreated tumors.

Immunotherapy has recently emerged as a highly effective cancer treatment strategy, with high overall response rates in multiple cancer types and durable tumor control enjoyed by a small subset of patients. ${ }^{6}$ Of particular interest is checkpoint blockade immunotherapy which uses small molecules or antibodies to stimulate the immunosuppressive microenvironment of tumors by modulating protein expressions and/or functions at dysregulated immune checkpoints. ${ }^{6 b, 7}$ Indoleamine 2,3-dioxygenase (IDO) is one such checkpoint, an immunoregulatory enzyme highly expressed in tumors that catalyzes the oxidative catabolism of tryptophan (Trp) to kynurenine (Kyn). ${ }^{8}$ This catalytic process leads to depletion of Trp and production of Kyn, thus preventing the clonal expansion of T cells and promoting T cell anergy and apoptosis. ${ }^{9}$ Small-molecule IDO inhibitors such as 1methyl-tryptophan, ${ }^{9 b, 10}$ INCB24360, ${ }^{11}$ and NLG919 ${ }^{12}$ can effectively block Trp catabolism 
but show modest effects as monotherapies, due in part to ineffective antigen presentation and insufficient antitumor immunity.

We herein report the design of a new $\mathrm{nMOF}$, TBC-Hf, constructed from a chlorin derivative, 5,10,15,20-tetra( $p$-benzoato)chlorin $\left(\mathrm{H}_{4} \mathrm{TBC}\right)$, and $\mathrm{Hf}_{6}\left(\mu_{3}-\mathrm{O}\right)_{4}\left(\mu_{3}-\mathrm{OH}\right)_{4}$ SBUs. We took advantage of the highly porous structure of the nMOF to load an IDO inhibitor (IDOi) into TBC-Hf to afford IDOi@ TBC-Hf. The IDOi@TBC-Hf system enables a novel cancer treatment strategy by combining nMOF-enabled PDT and IDOi-based immunotherapy (Figure 1). We demonstrated the eradication of the primary, treated tumors and the rejection of the distant, untreated tumors upon IDOi@TBC-Hf administration and light irradiation using two syngeneic colorectal cancer models, CT26 and MC38, and investigated the underlying immunological mechanisms.

\section{RESULTS}

\section{Synthesis and Characterization of nMOFs}

The new chlorin derivative 5,10,15,20-tetra( $p$-benzoato)chlorin $\left(\mathrm{H}_{4} \mathrm{TBC}\right)$ was synthesized as depicted in Scheme 1. Briefly, 5,10,15,20-tetra( $p$-methylbenzoato)chlorin $\left(\mathrm{Me}_{4} \mathrm{TBC}\right)$ was synthesized by a partial reduction of 5,10,15,20-tetra( $p$-methylbenzoato)porphyrin (Me ${ }_{4} \mathrm{TBP}$ ) with toluenesulfonhydrazide in $16 \%$ yield. Saponification of $\mathrm{Me}_{4} \mathrm{TBC}$ afforded $\mathrm{H}_{4} \mathrm{TBC}$ in $78 \%$ yield. $\mathrm{Me}_{4} \mathrm{TBC}$ and $\mathrm{H}_{4} \mathrm{TBC}$ were characterized by NMR and mass spectrometry (Figures S1-S5, Supporting Information).

A solvothermal reaction between $\mathrm{HfCl}_{4}$ and $\mathrm{H}_{4} \mathrm{TBC}$ in $\mathrm{N}, \mathrm{N}$-dimethylformamide (DMF) at $80{ }^{\circ} \mathrm{C}$ afforded the purple powder of TBC-Hf in $87 \%$ yield. TBC-Hf was washed with copious amounts of DMF, $1 \%$ triethylamine in ethanol (v/v), and ethanol successively and stored in ethanol as a stock suspension. As a control, TBP-Hf with the corresponding porphyrin ligand $5,10,15,20$-tetra( $p$-benzoato)porphyrin $\left(\mathrm{H}_{4} \mathrm{TBP}\right)$ was synthesized by a solvothermal reaction between $\mathrm{HfCl}_{4}$ and $\mathrm{H}_{4} \mathrm{TBP}$ in $\mathrm{N}, \mathrm{N}$-diethylformamide (DEF) at $120{ }^{\circ} \mathrm{C}$ and washed in the same fashion as for TBC-Hf.

TBC-Hf and TBP-Hf adopt the same structure as the previously reported TBP-Zr analogue (MOF-545), based on powder X-ray diffraction (PXRD) (Figure 2a). ${ }^{13}$ The carboxylate moieties from the TBC ligands bridge 8 out of 12 edges of octahedral $\mathrm{Hf}_{6}\left(\mu_{3}-\mathrm{O}\right)_{4}\left(\mu_{3}-\mathrm{OH}\right)_{4}$ SBUs. The remaining coordination sites on the SBUs are occupied by 4 water and 4 terminal hydroxy groups on the equatorial plane to afford a hexagonal framework of $\mathrm{Hf}_{6}\left(\mu_{3}-\mathrm{O}\right)_{4}\left(\mu_{3}-\right.$ $\mathrm{OH})_{4}(\mathrm{OH})_{4}-\left(\mathrm{H}_{2} \mathrm{O}\right)_{4}(\mathrm{TBC})_{2}$ (Figure S6). The nMOFs therefore feature large one-dimensional channels with diameters of $3.5 \mathrm{~nm}$ along the $c$ axis, along with smaller channels with diameters of $1.0 \mathrm{~nm}$ along the $c$ axis and $1.1 \mathrm{~nm} \times 0.9 \mathrm{~nm}$ windows perpendicular to the $c$ axis. TBC-Hf and TBP-Hf exhibit BET surface areas of 1077 and $1462 \mathrm{~m}^{2} / \mathrm{g}$, respectively (Figure S7). During the course of this study, a few reports of TBP-based nMOFs with a cubic structure for PDT have appeared. ${ }^{14}$ However, we expect that our highly porous TBP$\mathrm{Hf}$ control will outperform the cubic TBP-based nMOFs due to enhanced ${ }^{1} \mathrm{O}_{2}$ diffusion through the nMOF channels. In TBC-Hf and TBP-Hf, the porphyrin and chlorin rings are highly rigid in the nMOF structures to minimize energy transfer and self-quenching. 
Transmission electron microscopy (TEM) revealed nanorod/nanorice morphologies for TBPHf and TBC-Hf (Figure 2b,d). The rods are typically 50-100 nm long and 30-60 nm wide for TBC-Hf, and 50-100 nm long and 20-30 nm wide for TBP-Hf. High-resolution TEM images show the lattice fringes with distances matching the $d_{200}$ and $d_{001}$ spacings of the crystal structure (Figures 2c,e, S8, and S9). The average diameters of TBC-Hf and TBP-Hf are 83.2 and $72.7 \mathrm{~nm}$, respectively, as measured by dynamic light scattering (DLS) (Figure S10). The nMOFs are stable in biological environments, as evidenced by the lack of significant changes in PXRD pattern or morphology after incubation in Hank's balanced salt solution (HBSS) for $24 \mathrm{~h}$ (Figure 2a,f).

The Hf content was determined by inductively coupled plasma-mass spectrometry (ICP-MS) to be $30.4 \%$ ( $36.6 \%$ calculated). The TBC weight loss of $61.7 \%$ (56.8\% calculated) determined by thermogravimetric analysis (TGA) further confirms the framework formula (Figure S11a). We encapsulated an INCB24360 analogue, ${ }^{11}$ 4-amino- $N$-(3-chloro-4fluorophenyl)- $N^{\prime}$-hydroxy-1,2,5-oxadiazole-3-carboximidamide (Figure S11b), into the TBC-Hf channels to afford IDOi@ TBC-Hf for the co-delivery of IDOi with PSs. The IDOi weight percentage after loading was determined to be $4.7 \%$ by TGA and ${ }^{1} \mathrm{H}$ NMR (Figures S11a and S12). The release of IDOi from IDOi@TBC-Hf was studied in HBSS (Figure S13). IDOi slowly leached from TBC-Hf, reaching $83.3 \%$ release after incubation in HBSS for $24 \mathrm{~h}$.

UV-visible absorption spectroscopy indicates that TBC-Hf more effectively absorbs red light compared to TBP-Hf (Figure 3a). $\mathrm{H}_{4} \mathrm{TBC}$ has a major Soret peak at $\lambda_{\max }=420 \mathrm{~nm}$ and four Q-bands at 518, 546, 600, and $652 \mathrm{~nm}$. The Soret absorption of TBC-Hf almost overlaps with that of the free ligand $\left(\lambda_{\max }=421 \mathrm{~nm}\right)$, while the Q-bands slightly red-shift to $520,548,600$, and $653 \mathrm{~nm}$. In comparison, the Soret peaks of $\mathrm{H}_{4} \mathrm{TBP}$ and TBP-Hf are at $\lambda_{\max }=420$ and $418 \mathrm{~nm}$, respectively, and the Q-bands are at 516, 549, 592, and $646 \mathrm{~nm}$ for $\mathrm{H}_{4} \mathrm{TBP}$ and 517, 550, 593, and $647 \mathrm{~nm}$ for TBP-Hf. The lowest energy Q-band of the chlorin therefore red-shifts by $6 \mathrm{~nm}$ after reduction from the porphyrin counterpart $(652 \mathrm{~nm}$ compared to $646 \mathrm{~nm}$ ). The extinction coefficient of $\mathrm{H}_{4} \mathrm{TBC}$ at the lowest energy absorption $\left(\varepsilon=44700 \mathrm{M}^{-1} \cdot \mathrm{cm}^{-1}\right)$ is $\sim 9$ fold greater than that of $\mathrm{H}_{4} \mathrm{TBP}\left(\varepsilon=4800 \mathrm{M}^{-1} \cdot \mathrm{cm}^{-1}\right)$, while the lowest energy absorption of TBC-Hf $\left(\varepsilon=38500 \mathrm{M}^{-1} \cdot \mathrm{cm}^{-1}\right)$ is 6 -fold greater than that of TBP-Hf $\left(\varepsilon=6400 \mathrm{M}^{-1} \cdot \mathrm{cm}^{-1}\right)$. Notably, the lowest energy absorption of TBC-Hf $(653 \mathrm{~nm})$ is at a wavelength of $7 \mathrm{~nm}$ longer than that of our previously reported $\mathrm{DBC}-\mathrm{UiO}$, and the $\varepsilon$ of TBC-Hf is $\sim 1.6$ fold higher than that of DBC-UiO.

$\mathrm{H}_{4} \mathrm{TBC}$ exhibits two fluorescence emissions at 655 and $715 \mathrm{~nm}$ with an intensity ratio of $\sim 6.8$ when excited at $420 \mathrm{~nm}$ (Figure 3c). $\mathrm{H}_{4} \mathrm{TBP}$ fluorescence emissions are close to those of $\mathrm{H}_{4} \mathrm{TBC}$, though the $651 \mathrm{~nm} / 713 \mathrm{~nm}$ peak intensity ratio is $\sim 2$ (Figure $3 \mathrm{~b}$ ). After forming nMOFs, the fluorescence intensities drop significantly, consistent with other nMOF systems. ${ }^{4}$ For TBC-Hf, the fluorescence peaks slightly blue-shift to 650 and $712 \mathrm{~nm}$ and the intensities decrease by 5.3-fold and 4.7-fold, respectively; for TBP-Hf, the fluorescence peaks blue-shift to 648 and $704 \mathrm{~nm}$, and the fluorescence intensities drop by 9.0 -fold and 6.5 -fold, respectively. The decrease in fluorescence intensity likely results from the enhanced intersystem crossing after coordination of the chlorin/porphyrin ligands to $\mathrm{Hf}$ on the SBUs. Time-correlated single photon counting measurement results also supported this 
interpretation: the fluorescence lifetime at $650 \mathrm{~nm}$ dropped from $9.56 \mathrm{~ns}$ for $\mathrm{H}_{4} \mathrm{TBC}$ to 8.25 ns for TBC-Hf and from $9.25 \mathrm{~ns}$ for $\mathrm{H}_{4}$ TBP to $8.38 \mathrm{~ns}$ for TBP-Hf (Figure 3d,e and Table S1).

\section{Singlet Oxygen Generation}

The ${ }^{1} \mathrm{O}_{2}$ generation efficiencies of $\mathrm{H}_{4} \mathrm{TBC}$, TBC-Hf, $\mathrm{H}_{4} \mathrm{TBP}$, and TBP-Hf were determined by Singlet Oxygen Sensor Green (SOSG) assay. The nMOF samples and ligand controls were irradiated with a $\operatorname{LED}\left(\lambda_{\max }=650 \mathrm{~nm}, 20 \mathrm{~mW} / \mathrm{cm}^{2}\right)$, and the fluorescence enhancement upon reaction of SOSG with ${ }^{1} \mathrm{O}_{2}$ was measured by a fluorimeter (excitation/ emission at 504/525 nm). The fluorescence intensity plotted against irradiation time fit exponential decay equations, as we had previously observed in other nMOF systems, ${ }^{4}$ indicating a pseudo-first-order ${ }^{1} \mathrm{O}_{2}$ generation process (Figure 3f). TBC-Hf outperforms both TBP-Hf and $\mathrm{H}_{4} \mathrm{TBC}$ in terms of ${ }^{1} \mathrm{O}_{2}$ generation efficiency.

\section{In Vitro PDT Efficacy and Mechanistic Study}

We first confirmed efficient cellular uptake of TBC-Hf and TBP-Hf by cancer cells. TBC-Hf and TBP-Hf were incubated with colorectal cancer CT26 cells at a ligand concentration of $25 \mu \mathrm{M}$ for $24 \mathrm{~h}$. The Hf contents inside cells were determined to be $2.07 \pm 0.26$ and 1.79 $\pm 0.17 \mathrm{nmol} / 10^{4}$ cells, respectively, by ICP-MS analysis (Figure S14). The in vitro PDT efficacy of TBP-Hf, TBC-Hf, and both ligands against CT26 cells was next investigated. TBC-Hf outperformed TBP-Hf under $90 \mathrm{~J} / \mathrm{cm}^{2}$ light irradiation. Both nMOFs and ligands outperformed protoporphyrin IX (PpIX), a commonly used PS, upon irradiation, while no cytotoxicity was observed in dark control groups (Figure $\mathrm{S} 15$ ). The $\mathrm{IC}_{50}$ values of TBC-Hf, TBP-Hf, $\mathrm{H}_{4}$ TBC, $\mathrm{H}_{4}$ TBP, and PpIX for CT26 cells were $4.82 \pm 0.50,7.09 \pm 0.39,10.04$ $\pm 1.22,12.83 \pm 1.59$, and $23.72 \pm 0.60 \mu \mathrm{M}$, respectively, at an irradiation dose of $90 \mathrm{~J} / \mathrm{cm}^{2}$ (Figure 4a). These results were confirmed by a second colorectal cancer MC38 cell with $\mathrm{IC}_{50}$ values of $2.57 \pm 0.85$ and $17.9 \pm 5.0 \mu \mathrm{M}$ for $\mathrm{TBC}-\mathrm{Hf}$ and $\mathrm{H}_{4} \mathrm{TBC}$, respectively. The $\mathrm{IC}_{50}$ values exceeded $50 \mu \mathrm{M}$ for TBP-Hf, $\mathrm{H}_{4} \mathrm{TBP}$, and PpIX for MC38 cells (Figure $4 \mathrm{~b}$ ). To demonstrate the versatility of our nMOF system, unrelated B16F10 melanoma cells were employed to confirm the PDT efficacy, yielding $\mathrm{IC}_{50}$ values of $5.48 \pm 0.70,9.72 \pm 0.78$, $11.03 \pm 1.57,20.10 \pm 4.28$, and $16.48 \pm 0.77 \mu \mathrm{M}$ for TBC-Hf, TBP-Hf, $\mathrm{H}_{4} \mathrm{TBC}, \mathrm{H}_{4} \mathrm{TBP}$, and PpIX, respectively (Figure S16).

Unlike most conventional cytotoxic agents, PDT is known to induce ICD via apoptosis and necrosis, thereby mediating antitumor immune response..$^{5}$ We confirmed that both apoptosis and necrosis occur upon treatment with PDT by flow cytometry of Alexa Fluor 488 Annexin V-labeled dead cells. MC38 cells were incubated with TBC-Hf, TBP-Hf, $\mathrm{H}_{4} \mathrm{TBC}$, and $\mathrm{H}_{4} \mathrm{TBP}$ at $1 \mu \mathrm{M}$ (ligand concentration of $2 \mu \mathrm{M}$ ), followed by light irradiation at $90 \mathrm{~J} / \mathrm{cm}^{2}$ $\left(650 \mathrm{~nm}, 100 \mathrm{~mW} / \mathrm{cm}^{2}\right)$. Significant amounts of cells underwent apoptosis $/$ necrosis when treated with PDT of TBC-Hf, TBP-Hf, $\mathrm{H}_{4} \mathrm{TBC}$, and $\mathrm{H}_{4} \mathrm{TBP}$, with only $30.0 \%, 55.5 \%$, $32.7 \%$, and $57.6 \%$ healthy cells, respectively, compared to $80-90 \%$ healthy cells in dark control or PBS-treated cells with irradiation (Figures $4 \mathrm{c}$ and S17a). These results were further confirmed in CT26 cells under the same conditions (Figure S17b). Taken together, the chlorin-based TBC-Hf is a more efficient PS than the porphyrin-based TBP-Hf at equivalent $\mathrm{nMOF}$ and light doses. 
We also investigated the ability of PDT treatment to induce ICD by determining cell-surface expression of calreticulin (CRT). MC38 cells were incubated with TBC-Hf, TBP-Hf, $\mathrm{H}_{4} \mathrm{TBC}$, and $\mathrm{H}_{4} \mathrm{TBP}$ at $1 \mu \mathrm{M}$ (ligand concentration of $2 \mu \mathrm{M}$ ) followed by light irradiation at $90 \mathrm{~J} / \mathrm{cm}^{2}$. For flow cytometry analysis, cells were collected and stained with Alexa Fluor 488-CRT antibody and propidium iodide (PI, Figures $4 \mathrm{~d}$ and S18). The fluorescence intensity of stained cells was gated on PI-negative cells. For immunostaining analysis, the cells were stained with AlexaFluor 488-CRT and DAPI, and observed under confocal laser scanning microscopy (CLSM, Figures 4e and S19). In both instances, cells treated with nMOF or ligand showed significant CRT expression on the cell-surface upon irradiation but none with PBS control or without irradiation. Due to the higher ${ }^{1} \mathrm{O}_{2}$ generation efficiency and in vitro PDT efficacy of TBC-Hf, we focus our subsequent in vivo studies on TBC-Hf and use TBP-Hf as a control wherever appropriate.

\section{Abscopal Effect of IDOi@TBC-Hf}

The immunoregulatory enzyme IDO is often overexpressed in the tumor micro-environment, where it facilitates the survival and growth of tumor cells by suppressing antitumor immune responses. ${ }^{15}$ The small-molecule IDO inhibitor INCB24360, developed by Incyte, can reverse immunosuppression and inhibit tumor growth upon oral administration. ${ }^{16} \mathrm{We}$ propose that, by encapsulation of IDOi into the nMOF channels, IDOi@TBC-Hf can both release IDOi into the local tumor environment and enter blood circulation for systemic IDO inhibition. The effects of IDOi will alter the suppressive tumor microenvironment of both the treated and untreated tumors. We hypothesize that synergizing local PDT of IDOi@TBC-Hf with checkpoint blockade therapy can promote an efficient abscopal effect, regression of an untreated tumor at a distant site following the local treatment of another tumor in the same organism.

We evaluated the abscopal effect of IDOi@TBC-Hf and light irradiation in two immunocompetent mouse models using bilateral tumor models of colorectal cancers CT26 and MC38 in the flank regions of BALB/c mice and C57BL/6 mice, respectively. When the primary tumors reached $\sim 100 \mathrm{~mm}^{3}$, mice received a single injection of $\mathrm{H}_{4} \mathrm{TBC}, \mathrm{H}_{4} \mathrm{TBC}$ plus IDOi, TBC-Hf, or IDOi@TBC-Hf into the primary tumors at a ligand dose of $20 \mu \mathrm{mol} / \mathrm{kg}$ or a corresponding IDOi dose of $1.5 \mathrm{mg} / \mathrm{kg}$. Twelve hours after injection, the primary tumors were irradiated at a light dose of $90 \mathrm{~J} / \mathrm{cm}^{2}\left(650 \mathrm{~nm}, 100 \mathrm{~mW} / \mathrm{cm}^{2}\right)$. Mice treated with IDOi@TBC-Hf without light irradiation served as dark controls. The primary tumor receiving intratumoral injection with or without irradiation was designated as the "treated tumor", while the contralateral tumor which received neither direct injection nor irradiation was designated as the "untreated tumor". As depicted in Figures 5 and S20-S22, local nMOF injection with light irradiation led to near elimination of the treated primary tumors. At the end point, CT26 tumor-bearing mice treated with IDOi@TBC-Hf or TBC-Hf and PDT therapy had tumors only $1.1 \pm 0.2 \%$ and $0.7 \pm 0.4 \%$ the size of PBS-treated tumors, respectively. Similarly, MC38 tumor-bearing mice had tumors only $0.8 \pm 0.3 \%$ and 0.9 $\pm 0.4 \%$ of the size of PBS-treated tumors, respectively. $\mathrm{H}_{4} \mathrm{TBC}$ with light irradiation and IDOi@TBC-Hf dark group failed to inhibit the tumor growth, while $\mathrm{H}_{4} \mathrm{TBC}$ plus IDOi with light irradiation slightly inhibits the tumor growth (Table S2). Moreover, only PDT treatment of IDOi@ TBC-Hf successfully reduced the sizes of the untreated distant tumors. Tumors 
began shrinking on Day 6 and 5 after treatment in the CT26 and MC38 models, respectively, suggesting the treatment evoked systemic antitumor immunity in mice (Table S2-S3). TBCHf with light irradiation and IDOi@TBC-Hf dark control slightly inhibited the distant tumor growth, showing ineffectiveness of monotherapies.

\section{Antitumor Immunity}

We have shown that PDT of IDOi@TBC-Hf caused effective tumor regression of both primary, treated tumors and distant, untreated tumors in two syngeneic mouse models of colorectal cancer. We further investigated the underlying immunological mechanisms in the MC38 model by Enzyme-Linked ImmunoSpot (ELISPOT) assay and flow cytometry. We first performed an ELISPOT assay to detect the presence of tumor antigen-specific $\mathrm{T}$ cells 14 days after treatment. As shown in Figure 6a, the number of antigen-specific IFN- $\gamma$ producing T cells increased to 799 per million splenocytes in mice treated with IDOi@TBCHf (vs 128 per million splenocytes in PBS group, $P=0.0879$ ), indicating that PDT of IDOi@TBC-Hf induced in situ tumor vaccination to effectively generate tumor-specific T cell response.

Further analysis of the immune response was carried out by investigating the tumorinfiltrating leukocyte profiles in each tumor by flow cytometry. Previous research has shown that PDT can evoke acute inflammation, ${ }^{5}$ so we first evaluated the population of leukocytes responsible for innate immune response (neutrophils, B cells, dendritic cells, and macrophages) in both primary and distant tumors $12 \mathrm{~h}$ after PDT treatment. As shown in Figures 6b,c and S23, IDOi@TBC-Hf administration and light irradiation led to significant increases in the percentage of tumor-infiltrating neutrophils and $\mathrm{B}$ cells with respect to the total number of cells in the tumor compared to PBS (neutrophils: $P=0.0369$ vs PBS; B cells: $P=0.0215$ vs PBS). To our surprise, the percentage of infiltrating dendritic cells appeared to decrease compared to PBS control in the primary tumor (Figure S23), although the difference is not of statistical significance.

To better understand the roles these types of cells played in the antigen presentation after PDT, we further detected the major histocompatibility complex class II (MHC-II) expression on these cells $12 \mathrm{~h}$ after PDT treatment. MHC-II mediates establishment of specific immunity by presenting tumor antigens to $\mathrm{T}$ cell receptors on the surface of CD4+ Thelper cells. ${ }^{17}$ We found a significant decrease in MHC-II expression levels on dendritic cells, macrophages, and neutrophils in the primary treated tumors (DC: $P<0.0001$ vs PBS; macrophages: $P=0.0004$ vs PBS; neutrophils: $P=0.006$ vs PBS, Figure S24). These results imply that TBC-Hf-mediated PDT may have an impact on the method of antigen presentation, which is typically the role of dendritic cells.

We profiled the tumor-infiltrating leukocytes on 7 days post PDT treatment. The mice treated with IDOi@TBC-Hf plus PDT did not show significant difference in all cell types except B cells from the control mice (Figure S25). The percentage of B cells significantly increased with respect to the total number of cells in the primary tumors of IDOi@TBC-Hfand PDT-treated mice ( $P=0.0018$, Figure S25c), while the percentage of dendritic cells significantly decreased in the distant tumors of treated mice $(P=0.0083$, Figure S25f). We 
also found that the percentage of NK cells was extremely low on day 7 post PDT treatment both in IDOi@TBC-Hf-treated mice and PBS-treated mice (both <0.05\%, Figure S25e).

We further determined the tumor-infiltrating leukocyte profiles 12 days post PDT treatment. As shown in Figure 6d-f, IDOi@TBC-Hf significantly increased the proportion of infiltrating $\mathrm{CD}^{+} \mathrm{T}$ cells relative to the total number of cells in the distant tumor $(P=0.0012$ vs PBS), an essential step to mounting an antitumor immune response to induce the abscopal effect. In both primary and distant tumors, the percentages of infiltrating CD $45^{+}$leukocytes and $\mathrm{CD}^{+} \mathrm{T}$ cells with respect to the total number of cells in the tumors were significantly increased in mice treated with PDT of IDOi@ TBC-Hf (Treated tumor, CD45 ${ }^{+}, P=0.0061$ vs PBS; CD4 ${ }^{+}$T cells, $P=0.0206$ vs PBS; Untreated tumor, $\mathrm{CD} 45^{+}, P=0.0001$ vs PBS; $\mathrm{CD}^{+}$T cells, $P=0.0388$ vs PBS). Furthermore, the percentage of tumor-infiltrating NK cells significantly increased in the distant tumors of mice treated with IDOi@TBP-Hf and PDT ( $P=0.0034$ vs PBS, Figure S26). Interestingly, IDOi@ TBP-Hf administration and PDT also led to a significant increase in the percentages of tumor-infiltrating B cells and a decrease in the percentages of tumor-infiltrating dendritic cells with respect to the total number of cells in the primary tumors 12 days post the treatment (B cells, $P=0.0017$ vs PBS; DCs, $P=0.0041$ vs PBS, Figure S27).

We also performed $\mathrm{T}$ cell blocking experiments to confirm the involvement of $\mathrm{T}$ cells in the efficient abscopal response on a bilateral subcutaneous MC38 mouse model. MC38 tumorbearing mice were treated with IDOi@TBC-Hf and light irradiation as described before and received i.p. injections of Mouse IgG, anti-CD4, or anti-CD8 antibody at a dose of $200 \mu \mathrm{g} /$ mouse/injection on Day 0 and Day 5 post the PDT treatment. While mice treated with Mouse IgG showed regression of both primary and distant tumors, no abscopal effect was observed on mice with blocking of $\mathrm{CD}^{+}$or $\mathrm{CD}^{+} \mathrm{T}$ cells (Figure $6 \mathrm{~g}, \mathrm{~h}$ ). Furthermore, blocking of $\mathrm{CD}^{+}$and $\mathrm{CD}^{+} \mathrm{T}$ cells also diminished the effect of IDOi@ TBC-Hf in regressing the primary tumors. These results indicated that $\mathrm{CD}^{+}$and $\mathrm{CD}^{+} \mathrm{T}$ cells were essential not only to the abscopal effect but also to primary tumor rejection.

\section{DISCUSSION}

Approximately 140000 patients are diagnosed with colorectal cancer in the U.S. annually, with one-third dying from metastasis. ${ }^{18}$ Stimulation of the host immune system has been shown to generate an antitumor immunity capable of controlling metastatic tumor growth, and thus represents a promising treatment strategy for metastatic colon cancer. ${ }^{8}$ Clinical results suggest that immunotherapies have the potential to achieve systemic and adaptable cancer control. However, combination with other treatment modalities is necessary to maximize the benefits of immunotherapy and increase the tumor-specific immune response rate. ${ }^{6 \mathrm{~b}}$ Here we report a new treatment strategy that combines local PDT of a new nMOF, TBC-Hf, in combination with IDO inhibition with nMOF-delivered small molecules to achieve effective and consistent abscopal responses in mouse models of colorectal cancers. We have shown that IDOi released from locally injected IDOi@ TBC-Hf reversed the suppressive tumor microenvironment in both treated and untreated tumors, which further synergized with TBC-Hf-mediated PDT to stimulate the immune system for activating both acute innate and prolonged adaptive immune response to achieve efficient local tumor

J Am Chem Soc. Author manuscript; available in PMC 2017 November 06. 
regression and a consistent abscopal response. Our treatment method maximizes the benefits of local treatment with systemic immune response for the rejection of both primary and distant tumors while minimizing side effects, potentially affording an effective systemic therapy for metastatic colorectal cancers.

Owing to the outstanding photophysical properties of the chlorin-based TBC ligand, TBCHf shows potent PDT efficacy and outperforms its porphyrin counterpart TBP-Hf. The tetracarboxylate ligand constructs a robust framework with very large channels for smallmolecular inhibitor loading and ROS diffusion, and the coordination to $\mathrm{Hf}_{6}$ SBUs enhances intersystem crossing of TBC to enhance ${ }^{1} \mathrm{O}_{2}$ generation. As we ${ }^{19}$ and others ${ }^{20}$ have demonstrated the synthetic tunability and potential biomedical applications of nMOFs in the past decade, we believe that the nMOF compositions and structures can be further optimized in order to enhance light absorption and ${ }^{1} \mathrm{O}_{2}$ generation/diffusion. We thus believe that nMOF-based synergistic PDT and immunotherapy have the potential for future clinical translation for the treatment of metastatic cancers.

We propose that the combination of IDOi@TBC-Hf administration and light irradiation causes highly efficient tumor regression of both primary treated tumors and distant untreated tumors owing to two factors. First, TBC-Hf based PDT causes ICD of cancer cells in the primary tumors, which activates innate immune system and promotes antigen presentation (Figure 1). The massive stressed and dying necrotic tumor cells in the PDT-treated primary tumor sites are engulfed by the innate immune effector cells followed by presenting tumorderived antigenic peptides to $\mathrm{T}$ cells, thus stimulating a tumor-specific $\mathrm{T}$ cell response. Second, the IDOi is released from intratumorally injected IDOi@TBC-Hf to systemically inhibit IDO activity to reverse the immunosuppressive tumor environments. Alternatively, the recruited immune cells likely undergo IDO inhibition in the treated tumors and migrate to the distant tumors to cause an abscopal effect. The two treatment modalities, PDT and IDOi checkpoint blockade therapy, synergize with each other to kill cancer cells locally and create an immunogenic tumor microenvironment systemically, leading to strong and consistent abscopal effects.

Dendritic cells are one of the most important antigen-presenting cells and prevalently believed to play a key role in antitumor immune response. ${ }^{21}$ However, we observed a decrease of dendritic cell population percentage at different time points along with a significant decrease of MHC-II expression level on dendritic cells after PDT treatment with IDOi@TBC-Hf, indicating an altered role for dendritic cells after PDT treatment. Meanwhile, the increase of both neutrophils and B cell population percentages implies a compensating effect of other antigen presenting cells to present tumor-associated antigens and initiate the antitumor immune response. Previous studies suggested that neutrophils, rather than dendritic cells, directly affect $\mathrm{T}$ cell proliferation upon PDT treatment. ${ }^{22} \mathrm{We}$ also observed significant increase in the percentage of tumor infiltrating NK cells from $0.02 \%$ on day 7 to $3.83 \%$ on day 12 post PDT treatment in distant tumors, suggesting the important role of tumor-infiltrating NK cells in tumor rejection in addition to those played by $\mathrm{CD} 8^{+} \mathrm{T}$ cells, CD4 ${ }^{+} \mathrm{T}$ cells, and B cells after IDOi@ TBC-Hf and PDT treatment. Our future efforts will be directed toward elucidating the roles of neutrophils and $\mathrm{B}$ cells in initiating antitumor immune response after the PDT of IDOi@TBC-Hf. 


\section{CONCLUSION}

In this work, we have rationally designed a chlorin-based nMOF with large channels for highly efficient PDT, while simultaneously loading an IDO inhibitor into its channels to achieve a combination of PDT and checkpoint blockade immunotherapy. We consistently observed an abscopal effect in mice receiving treatment with PDT of IDOi@ TBC-Hf. The in situ vaccination induced by PDT treatment and IDOi immunotherapy synergize with each other and effectively generate systemic antitumor immunity. We believe the present strategy has the potential to significantly increase the systemic tumor-specific immune response rates of checkpoint blockade cancer immunotherapy and lead to clinical benefits for the treatment of metastatic colorectal cancers and other difficult-to-treat cancers.

\section{MATERIALS AND METHODS}

\section{Materials, Cell Lines, and Animals}

All of the starting materials were purchased from Sigma-Aldrich and Fisher (USA), unless otherwise noted, and used without further purification. INCB24360 analogue, 4-amino- $N$-(3chloro-4-fluorophenyl)- $N^{\prime}$-hydroxy-1,2,5-oxadiazole-3-carboximidamide was purchased from Medkoo Biosciences, USA.

Murine colon adenocarcinoma cells CT26 and MC38 and murine melanoma cells B16F10 were purchased from the American Type Culture Collection (Rockville, MD, USA) and cultured in Dulbecco's Modified Eagle's Medium (DMEM, Gibco, Grand Island, NY, USA) supplemented with $10 \%$ FBS.

C57BL/6 female mice (6 weeks, 20-22 g) and BALB/c female mice (6 weeks, 20-22 g) were provided by Harlan Laboratories, Inc. (USA). The study protocol was reviewed and approved by the Institutional Animal Care and Use Committee (IACUC) at the University of Chicago.

\section{Synthesis of TBC-Hf}

To a 2-dram glass vial was added $1 \mathrm{~mL}$ of $\mathrm{HfCl}_{4}$ solution ( $2 \mathrm{mg} / \mathrm{mL}$ in DMF, $\left.6.2 \mu \mathrm{mol}\right), 1$ $\mathrm{mL}$ of the $\mathrm{H}_{4}$ TBC solution ( $1.9 \mathrm{mg} / \mathrm{mL}$ in DMF, $2.4 \mu \mathrm{mol}$ ), and $60 \mu \mathrm{L}$ of $88 \%$ formic acid $(1.4 \mathrm{mmol})$. The reaction mixture was kept in an $80{ }^{\circ} \mathrm{C}$ oven for 2 days. The purple powder was collected by centrifugation and washed with DMF, $1 \%$ triethylamine in ethanol (v/v), and ethanol.

\section{Singlet Oxygen Generation}

A light-emitting diode (LED) array with peak emission at $650 \mathrm{~nm}$ was used as the light source of singlet oxygen generation test. The irradiance of LED is $20 \mathrm{~mW} / \mathrm{cm}^{2}$. SOSG reagent (Life Technologies) was employed for the detection of singlet oxygen. $\mathrm{H}_{4} \mathrm{TBP}$, $\mathrm{H}_{4} \mathrm{TBC}$, TBP-Hf, and TBC-Hf samples were prepared in $1 \mu \mathrm{M}$ solutions/suspensions in water (for the nMOFs, the concentration was calculated as ligand equivalents). To $2 \mathrm{~mL}$ each of these solutions/suspensions, SOSG stock solution ( $5 \mu \mathrm{L}$ at $5 \mathrm{mM}$ ) was added (final concentration $=12.5 \mu \mathrm{M}$ ) before fluorescence measurement. For a typical measurement, fluorescence intensity was acquired on a spectrofluorophotometer (RF-5301PC, Shimadzu, 
Japan) with excitation at $504 \mathrm{~nm}$ and emission at $525 \mathrm{~nm}$ (slit width $1.5 \mathrm{~nm} / 3 \mathrm{~nm}$ for ex/em). Fluorescence was measured after irradiation by LED for 0 (as background), 0.5, 1, 1.5, 2, 3, $4,5,7$, and $10 \mathrm{~min}$.

\section{In Vitro PDT Efficacy}

The cytotoxicity of TBC-Hf and TBC was evaluated in murine colorectal cancer cell CT26 and murine melanoma cell B16F10, respectively. CT26 cells or B16F10 cells were seeded on 96-well plates at 1000 cells/well. The cells were treated with TBC-Hf and $\mathrm{H}_{4} \mathrm{TBC}$ at various ligand concentrations $(2,4,10,15,20$, and $50 \mu \mathrm{M}$ based on ligand concentrations). A further incubation of $4 \mathrm{~h}$ was allowed followed by replacing the culture medium with 100 $\mu \mathrm{L}$ of fresh medium. The cells were irradiated with LED light $(650 \mathrm{~nm})$ at $100 \mathrm{~mW} / \mathrm{cm}^{2}$ for $15 \mathrm{~min}$ (total light dose $90 \mathrm{~J} / \mathrm{cm}^{2}$ ) or kept in dark, respectively. The cells were further incubated to achieve a total incubation time of $72 \mathrm{~h}$. The cell viability was detected by $3-$ (4,5-dimethylthiazol-2-yl)-5-(3-carboxymethoxyphenyl)-2-(4-sulfophenyl)-2 $H$-tetrazolium (MTS) assay (Promega, USA).

\section{Abscopal Effect}

The PDT efficacy of IDOi@TBC-Hf was investigated using a bilateral CT26 mouse colorectal cancer model and a bilateral MC38 mouse colorectal cancer model. Tumorbearing mice were established by subcutaneous inoculation of CT26 or MC38 cell suspension $\left(1 \times 10^{6}\right.$ cells per mouse on the right flank and $2 \times 10^{5}$ cells per mouse on the left flank) into 6-week female BALB/c or 6-week female C57BL/6 mice, respectively. When the right tumors reached $100 \mathrm{~mm}^{3}$, the CT26 tumor-bearing mice received intratumoral injection only into the right tumors of PBS, $\mathrm{H}_{4} \mathrm{TBC}, \mathrm{H}_{4} \mathrm{TBC}+\mathrm{IDOi}$, TBC-Hf, or IDOi@TBC-Hf at a ligand dose of $20 \mu \mathrm{mol} / \mathrm{kg}$ and IDOi dose of $1.5 \mathrm{mg} / \mathrm{kg}$. Twelve hours post injection, CT26 tumor-bearing mice were anesthetized with $2 \%(\mathrm{v} / \mathrm{v})$ isoflurane, and right flank tumors were irradiated with a $650 \mathrm{~nm} \mathrm{LED} \mathrm{at} 0.1 \mathrm{~W} / \mathrm{cm}^{2}$ for $15 \mathrm{~min}\left(90 \mathrm{~J} / \mathrm{cm}^{2}\right)$. IDOi@TBC-Hf without light irradiation served as a dark control. The nMOF injection and light irradiations were performed every 3 days for a total two injections and irradiations. For MC38 tumor model, mice received intratumoral injection only into the right tumors of PBS, TBC-Hf, or IDOi@TBC-Hf at a ligand dose of $20 \mu \mathrm{mol} / \mathrm{kg}$ and IDOi dose of $1.5 \mathrm{mg} / \mathrm{kg}$. Twelve hours post injection, MC38 tumor-bearing mice were anesthetized with $2 \%(\mathrm{v} / \mathrm{v})$ isoflurane, and right flank tumors were irradiated with a $650 \mathrm{~nm} \mathrm{LED} \mathrm{at} 0.1 \mathrm{~W} / \mathrm{cm}^{2}$ for 15 $\min \left(90 \mathrm{~J} / \mathrm{cm}^{2}\right)$. IDOi@TBC-Hf without light irradiation served as a dark control. The nMOF injection and light irradiations were performed only once on MC38 tumor-bearing mice. For both CT26 and MC38 models, no nMOF injection or light irradiation was performed on the left tumors.

To evaluate the therapeutic efficacy, the tumor size was measured with a digital caliper every day. Tumor volumes were calculated as follows: (width ${ }^{2} \times$ length)/2. Finally, all mice were sacrificed when the tumor size of control group exceeded $2 \mathrm{~cm}^{3}$, and the excised tumors were photographed and weighed. 


\section{T Cell Blocking}

The abscopal effect of IDOi@TBC-Hf was evaluated on bilateral subcutaneous MC38 model on $\mathrm{C} 57 \mathrm{BL} / 6$ mice with $\mathrm{CD} 4^{+} \mathrm{T}$ cell or $\mathrm{CD}^{+} \mathrm{T}$ cell depletion. When the right tumors reached $\sim 100 \mathrm{~mm}^{3}$, IDOi@TBC-Hf was intratumorally injected to the mice at a dose of 20 $\mu \mathrm{mol} / \mathrm{kg}$. Anti-CD4 (for $\mathrm{CD} 4^{+} \mathrm{T}$ cell depletion), anti-CD8 (for $\mathrm{CD}^{+} \mathrm{T}$ cell depletion), or mouse IgG (control) were intraperitoneally injected to the mice (200 $\mu \mathrm{g} /$ mouse/injection) on Day 0 and Day 5 post the first treatment. Twelve hours post injection, mice were anesthetized with $2 \%(\mathrm{v} / \mathrm{v})$ isoflurane, and the right tumors were irradiated with LED light irradiation (100 mW/ $\left./ \mathrm{cm}^{2}, 90 \mathrm{~J} / \mathrm{cm}^{2}, 650 \mathrm{~nm}\right)$. Single IDOi@TBC-Hf injections followed by single light irradiations were carried out. To evaluate the therapeutic efficacy, the tumor size was measured with a digital caliper every other day. Tumor volumes were calculated as (width ${ }^{2} \times$ length) $/ 2$.

\section{ELISPOT}

Tumor-specific immune responses to IFN- $\gamma$ was measured in vitro by ELISPOT assay (Mouse IFN gamma ELISPOT Ready-SET-Go!; Cat. No. 88-7384-88; eBioscience). A Millipore Multiscreen HTS-IP plate was coated overnight at $4{ }^{\circ} \mathrm{C}$ with anti-Mouse IFN- $\gamma$ capture antibody. Single-cell suspensions of splenocytes were obtained from MC38 tumorcarrying mice and seeded onto the antibody-coated plate at a concentration of $2 \times 10^{5}$ cells/ well. Cells were incubated with or without KSPWFTTL (KSP) stimulation $(10 \mu \mathrm{g} / \mathrm{mL}$; purity >95\%; PEPTIDE 2.0) for $48 \mathrm{~h}$ at $37{ }^{\circ} \mathrm{C}$ and then discarded. The plate was then incubated with biotin-conjugated anti-IFN- $\gamma$ detection antibody at room temperature for $2 \mathrm{~h}$, followed by incubation with Avidin-HRP for $2 \mathrm{~h}$ at room temperature. AEC substrate solution (Sigma, Cat. AEC101) was added for cytokine spot detection.

\section{Flow Cytometry}

Tumors were harvested, treated with $1 \mathrm{mg} / \mathrm{mL}$ collagenase I (Gibco, USA) for $1 \mathrm{~h}$, and ground by the rubber end of a syringe. Cells were filtered through nylon mesh filters and washed with PBS. The single-cell suspension was incubated with anti-CD16/32 (clone 93; eBiosciences) to reduce nonspecific binding to FcRs. Cells were further stained with the following fluorochrome-conjugated antibodies: CD45 (30-F11), CD3e (145-2C11), CD4 (GK1.5), CD8 (53-6.7), Foxp3 (FJK-16s), CD11b (M1/70), Ly6C (HK1.4), Ly6G (RB6-8C5), F4/80 (BM8), B220 (RA3-6B2), NKp46 (29A1.4), and PI staining solution (all from eBioscience). LSR FORTESSA (BD Biosciences) was used for cell acquisition, and data analysis was carried out using FlowJo software (TreeStar, Ashland, OR).

\section{MHC-II Expression}

Tumors were harvested $12 \mathrm{~h}$ after LED irradiation, treated with $1 \mathrm{mg} / \mathrm{mL}$ collagenase $\mathrm{I}$, and ground by the rubber end of a syringe. Cells were filtered through nylon mesh filters and washed with PBS. The single cell suspension was incubated with anti-CD16/32 (clone 93; eBiosciences) for $10 \mathrm{~min}$ and then stained with CD45, CD3e, CD11b, Ly6G, B220, F4/80, CD11c, and MHC-II. The expression levels of MHC-II on CD11b+Ly-6G+, CD3e-B220+, $\mathrm{CD} 3 \mathrm{e}-\mathrm{CD} 11 \mathrm{c}+$, and $\mathrm{CD} 3 \mathrm{e}-\mathrm{CD} 11 \mathrm{c}-\mathrm{F} 4 / 80$ populations were determined, respectively. 


\section{Supplementary Material}

Refer to Web version on PubMed Central for supplementary material.

\section{Acknowledgments}

We thank Mr. Christopher Poon and Mr. Zekai Lin for experimental help. We acknowledge the National Cancer Institute (U01-CA198989), the University of Chicago Medicine Comprehensive Cancer Center (NIH CCSG: P30 CA014599), the Cancer Research Foundation, and the Ludwig Institute for Metastasis Research for funding support.

\section{References}

1. (a) Hamblin MR, Hasan T. Photoch Photobio Sci. 2004; 3(5):436-450.(b) Celli JP, Spring BQ, Rizvi I, Evans CL, Samkoe KS, Verma S, Pogue BW, Hasan T. Chem Rev. 2010; 110(5):2795-2838. [PubMed: 20353192] (c) Dolmans DEJGJ, Fukumura D, Jain RK. Nat Rev Cancer. 2003; 3(5):380387. [PubMed: 12724736] (d) Ethirajan M, Chen Y, Joshi P, Pandey RK. Chem Soc Rev. 2011; 40(1):340-362. [PubMed: 20694259]

2. Stolik S, Delgado J, Perez A, Anasagasti L. J Photochem Photobiol, B. 2000; 57(2):90-93. [PubMed: 11154088]

3. (a) Ng KK, Zheng G. Chem Rev. 2015; 115(19):11012-11042. [PubMed: 26244706] (b) Lovell JF, Jin CS, Huynh E, Jin H, Kim C, Rubinstein JL, Chan WC, Cao W, Wang LV, Zheng G. Nat Mater. 2011; 10(4):324-332. [PubMed: 21423187] (c) Huynh E, Leung BY, Helfield BL, Shakiba M, Gandier JA, Jin CS, Master ER, Wilson BC, Goertz DE, Zheng G. Nat Nanotechnol. 2015; 10(4): 325-332. [PubMed: 25822929] (d) Carter KA, Shao S, Hoopes MI, Luo D, Ahsan B, Grigoryants VM, Song W, Huang H, Zhang G, Pandey RK, Geng J, Pfeifer BA, Scholes CP, Ortega J, Karttunen M, Lovell JF. Nat Commun. 2014; 5:3546. [PubMed: 24699423] (e) Kim J, Piao Y, Hyeon T. Chem Soc Rev. 2009; 38(2):372-390. [PubMed: 19169455] (f) Wang W, Wang L, Li Z, Xie Z. Chem Commun. 2016; 52(31):5402-5405.(g) Padilla R, Maza WA, Dominijanni AJ, Winkel BS, Morris AJ, Brewer KJ. J Photochem Photobiol, A. 2016; 322:67-75.(h) Han K, Wang SB, Lei Q, Zhu JY, Zhang XZ. ACS Nano. 2015; 9(10):10268-10277. [PubMed: 26348984] (i) Chen JX, Wang HY, Li C, Han K, Zhang XZ, Zhuo RX. Biomaterials. 2011; 32(6):1678-1684. [PubMed: 21084116] (j) Wang C, Tao H, Cheng L, Liu Z. Biomaterials. 2011; 32(26):6145-6154. [PubMed: 21616529] (k) Idris NM, Gnanasammandhan MK, Zhang J, Ho PC, Mahendran R, Zhang Y. Nat Med. 2012; 18(10):1580-1585. [PubMed: 22983397] (1) Huang P, Lin J, Wang S, Zhou Z, Li Z, Wang Z, Zhang C, Yue X, Niu G, Yang M, et al. Biomaterials. 2013; 34(19):4643-4654. [PubMed: 23523428] (m) Park YI, Kim HM, Kim JH, Moon KC, Yoo B, Lee KT, Lee N, Choi Y, Park W, Ling D, et al. Adv Mater. 2012; 24(42):5755-5761. [PubMed: 22915170] (n) Levine DH, Ghoroghchian PP, Freudenberg J, Zhang G, Therien MJ, Greene MI, Hammer DA, Murali R. Methods. 2008; 46(1): 25-32. [PubMed: 18572025] (o) Cheng Y, Samia AC, Meyers JD, Panagopoulos I, Fei B, Burda C. J Am Chem Soc. 2008; 130(32):10643-10647. [PubMed: 18642918] (p) Rieffel J, Chen F, Kim J, Chen G, Shao W, Shao S, Chitgupi U, Hernandez R, Graves SA, Nickles RJ, et al. Adv Mater. 2015; 27(10):1785-1790. [PubMed: 25640213] (q) Luo D, Carter KA, Miranda D, Lovell JF. Adv Sci. 2016; doi: 10.1002/advs.201600106

4. (a) Lu K, He C, Lin W. J Am Chem Soc. 2014; 136(48):16712-16715. [PubMed: 25407895] (b) Lu K, He C, Lin W. J Am Chem Soc. 2015; 137(24):7600-7603. [PubMed: 26068094]

5. Castano AP, Mroz P, Hamblin MR. Nat Rev Cancer. 2006; 6(7):535-545. [PubMed: 16794636]

6. (a) Couzin-Frankel J. Science. 2013; 342(6165):1432-1433. [PubMed: 24357284] (b) Pardoll DM. Nat Rev Cancer. 2012; 12(4):252-264. [PubMed: 22437870]

7. Sharma P, Allison JP. Science. 2015; 348(6230):56-61. [PubMed: 25838373]

8. Zou W. Nat Rev Cancer. 2005; 5(4):263-274. [PubMed: 15776005]

9. (a) Gilboa E. Nat Rev Cancer. 2004; 4(5):401-411. [PubMed: 15122211] (b) Munn DH, Shafizadeh E, Attwood JT, Bondarev I, Pashine A, Mellor AL. J Exp Med. 1999; 189(9):1363-1372. [PubMed: 10224276] 
10. Munn DH, Zhou M, Attwood JT, Bondarev I, Conway SJ, Marshall B, Brown C, Mellor AL. Science. 1998; 281(5380):1191-1193. [PubMed: 9712583]

11. Yue EW, Douty B, Wayland B, Bower M, Liu X, Leffet L, Wang Q, Bowman KJ, Hansbury MJ, Liu C, et al. J Med Chem. 2009; 52(23):7364-7367. [PubMed: 19507862]

12. Khleif S, Munn D, Nyak-Kapoor A, Mautino MR, Kennedy E, Vahanian NN, Link CJ. ASCO Annual Meeting Proceedings. 2014:TPS3121.

13. Morris W, Volosskiy B, Demir S, Gándara F, McGrier PL, Furukawa H, Cascio D, Stoddart JF, Yaghi OM. Inorg Chem. 2012; 51(12):6443-6445. [PubMed: 22676251]

14. (a) Park J, Jiang Q, Feng D, Mao L, Zhou HC. J Am Chem Soc. 2016; 138(10):3518-3525. [PubMed: 26894555] (b) Liu J, Yang Y, Zhu W, Yi X, Dong Z, Xu X, Chen M, Yang K, Lu G, Jiang L, et al. Biomaterials. 2016; 97:1-9. [PubMed: 27155362]

15. Uyttenhove C, Pilotte L, Théate I, Stroobant V, Colau D, Parmentier N, Boon T, Van den Eynde BJ. Nat Med. 2003; 9(10):1269-1274. [PubMed: 14502282]

16. Newton RC, Scherle PA, Bowman K, Liu X, Beatty GL, O’Dwyer PJ, Gajewski T, Bowman J, Schaub R, Leopold L. ASCO Annual Meeting Proceedings. 2012:2500.

17. Janeway, CA., Travers, P., Walport, M., Capra, JD. Immunobiology: the immune system in health and disease. Taylor \& Francis; 2005.

18. Siegel R, DeSantis C, Jemal A. Cancer J Clin. 2014; 64(2):104-117.

19. (a) Huxford RC, Della Rocca J, Lin W. Curr Opin Chem Biol. 2010; 14(2):262-268. [PubMed: 20071210] (b) Lin W, Rieter WJ, Taylor KM. Angew Chem, Int Ed. 2009; 48(4):650-658.(c) Della Rocca J, Liu D, Lin W. Acc Chem Res. 2011; 44(10):957-968. [PubMed: 21648429] (d) He C, Liu D, Lin W. Chem Rev. 2015; 115(19):11079-11108. [PubMed: 26312730]

20. (a) Cui Y, Yue Y, Qian G, Chen B. Chem Rev. 2012; 112(2):1126-1162. [PubMed: 21688849] (b) Furukawa H, Cordova KE, O'Keeffe M, Yaghi OM. Science. 2013; 341(6149):1230444. [PubMed: 23990564] (c) Horcajada P, Gref R, Baati T, Allan PK, Maurin G, Couvreur P, Ferey G, Morris RE, Serre C. Chem Rev. 2011; 112(2):1232-1268. [PubMed: 22168547]

21. Palucka K, Banchereau J. Nat Rev Cancer. 2012; 12(4):265-277. [PubMed: 22437871]

22. Kousis PC, Henderson BW, Maier PG, Gollnick SO. Cancer Res. 2007; 67(21):10501-10510. [PubMed: 17974994] 


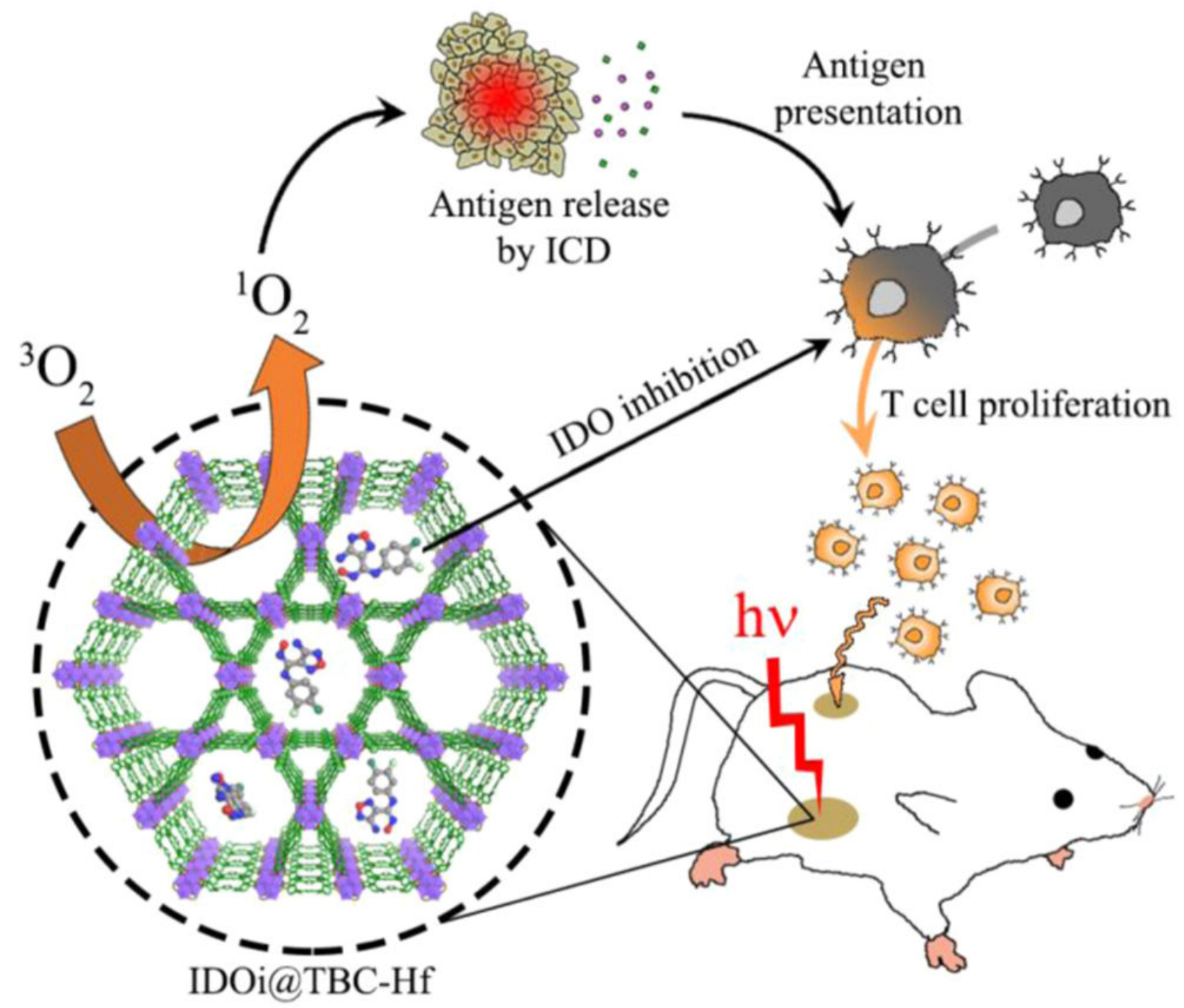

Figure 1.

Schematic presentation of combined PDT and immunotherapy by IDOi@TBC-Hf. Local injection of IDOi@TBC-Hf and light irradiation generate reactive oxygen species, causing immunogenic cell death (ICD) and releasing tumor-associated antigens which are presented to T cells. Meanwhile, the IDO inhibitor released from IDOi@ TBC-Hf modulates tryptophan/kynurenine catabolism to activate the immunosuppressive tumor microenvironment. The combination of antigen presentation from PDT and checkpoint blockade by IDO inhibition causes T cell proliferation and infiltration, leading to not only eradication of local, treated tumors but also rejection of distant, untreated tumors. 

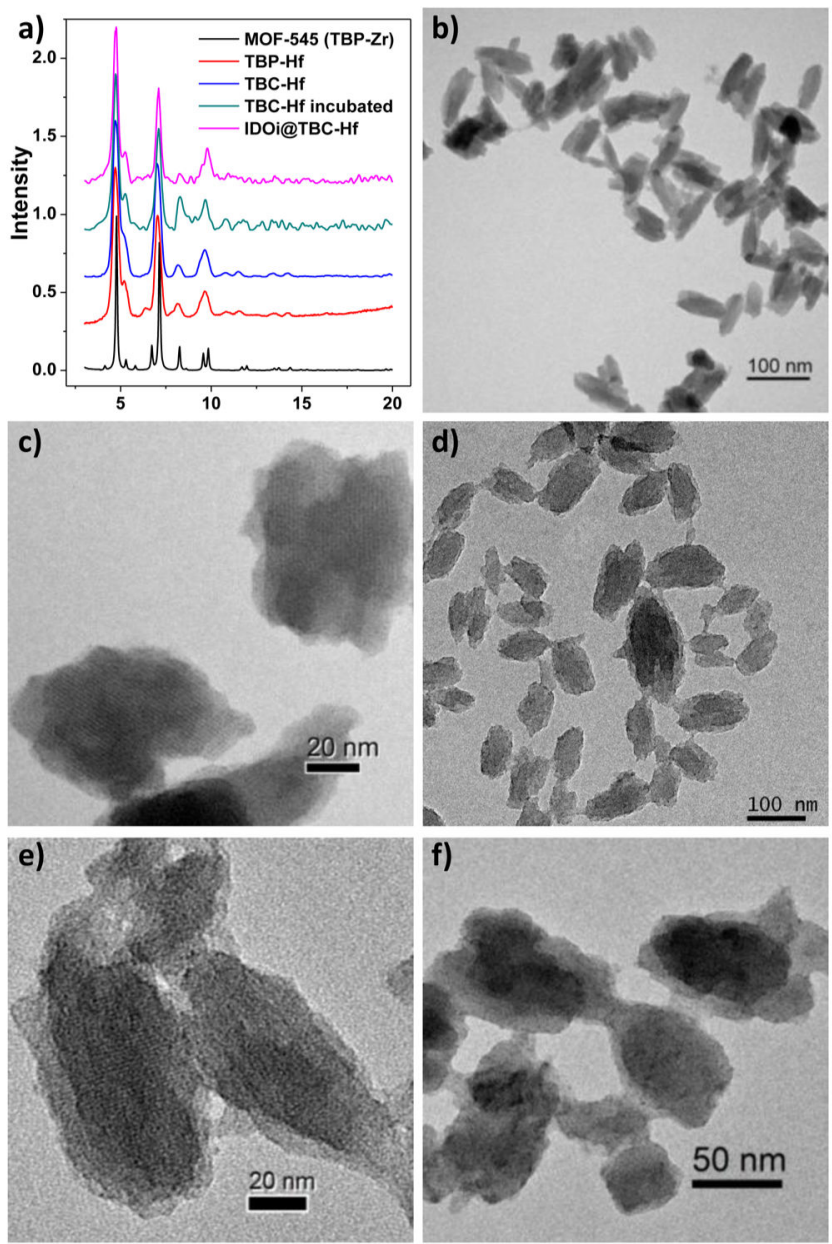

Figure 2.

Morphology and structure of TBP-Hf and TBC-Hf. (a) PXRD patterns of TBP-Hf, TBC-Hf, and IDOi@TBC-Hf in comparison to MOF-545. TEM images of TBP-Hf (b,c), TBC-Hf (d,e), and TBC-Hf after incubation in Hank's balanced salt solution for $24 \mathrm{~h}$ (f). 

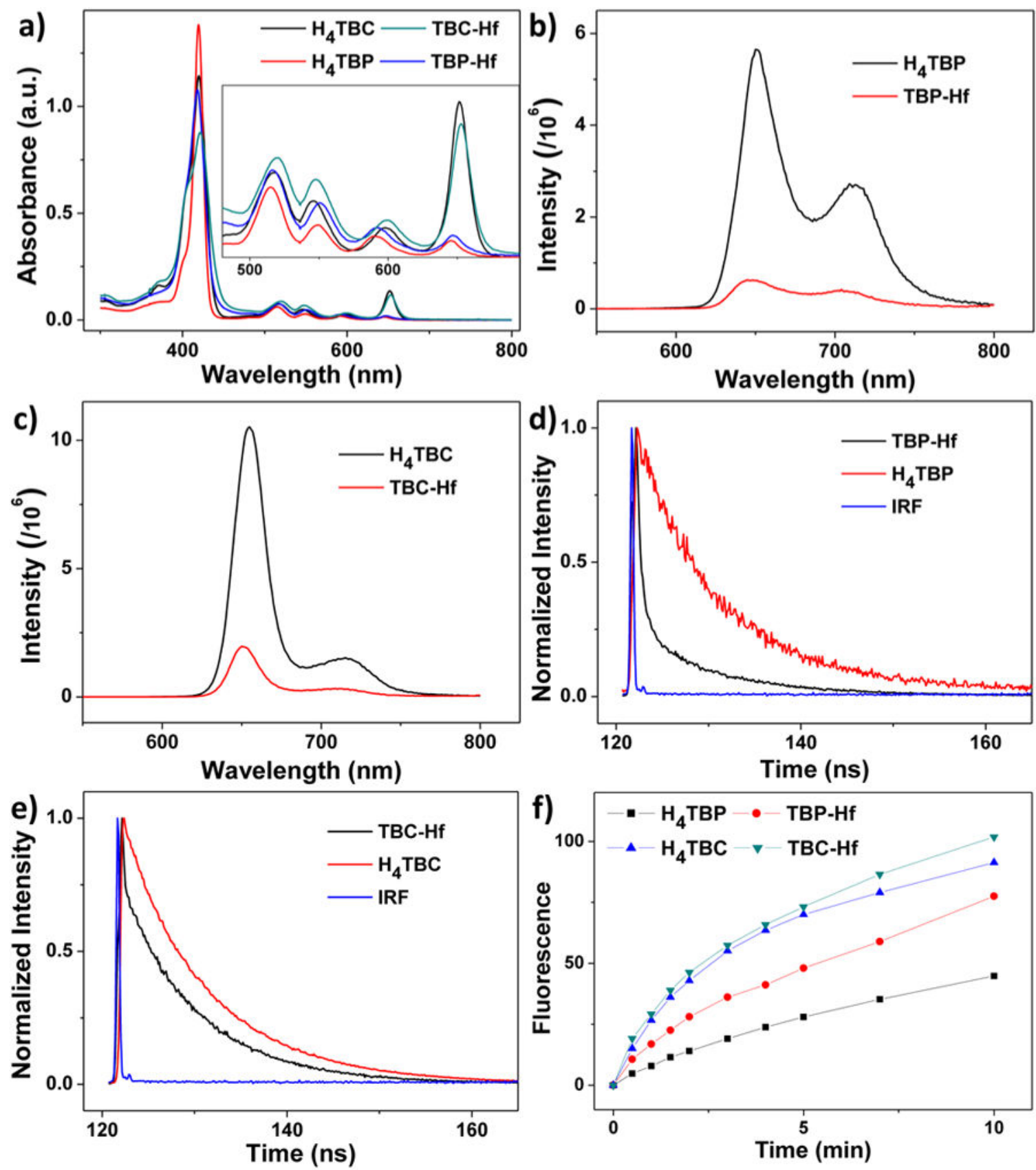

Figure 3.

Photophysics and photochemistry of the ligands and nMOFs. (a) UV-visible absorption spectra of $\mathrm{H}_{4} \mathrm{TBP}, \mathrm{H}_{4} \mathrm{TBC}$, TBP-Hf, and TBC-Hf. Inset shows expanded views of the Qband regions. Fluorescence spectra of $\mathrm{H}_{4} \mathrm{TBP}$ and TBP-Hf (b), and $\mathrm{H}_{4} \mathrm{TBC}$ and TBC-Hf (c), with excitation at $420 \mathrm{~nm}$. Time-resolved fluorescence decay traces of $\mathrm{H}_{4} \mathrm{TBP}$ and TBP-Hf (d), and $\mathrm{H}_{4} \mathrm{TBC}$ and $\mathrm{TBC}-\mathrm{Hf}$ (e), along with instrument response function (IRF). (f) Singlet oxygen generation by $\mathrm{H}_{4} \mathrm{TBP}, \mathrm{H}_{4} \mathrm{TBC}$, TBP-Hf, and TBC-Hf with a $650 \mathrm{~nm}$ LED irradiation at $20 \mathrm{~mW} / \mathrm{cm}^{2}$, detected by Singlet Oxygen Sensor Green assay. 
a)

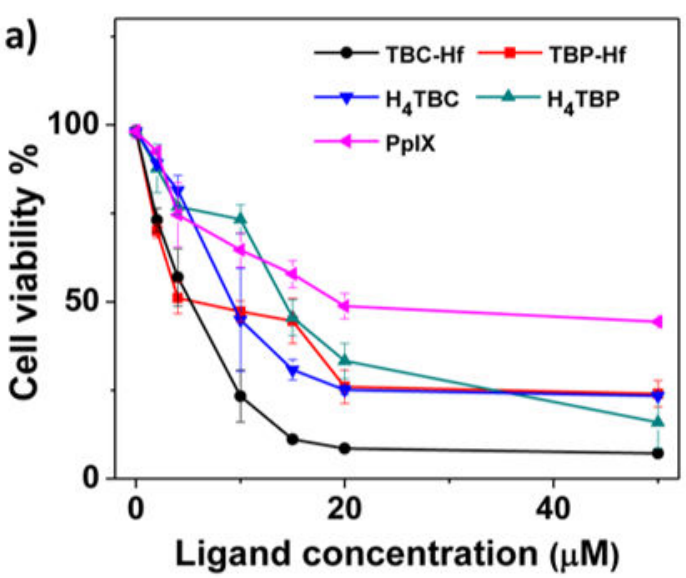

c)

$\mid$

$\bar{a}$
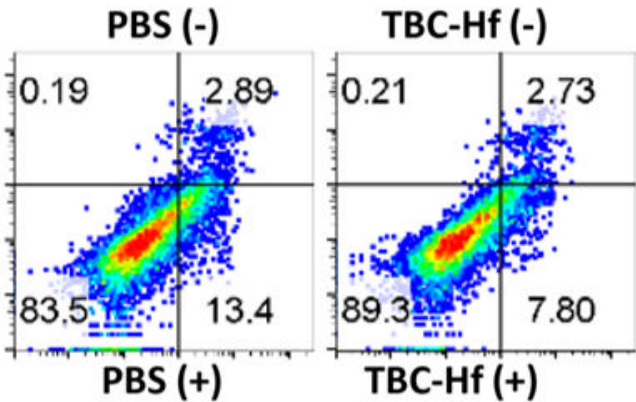
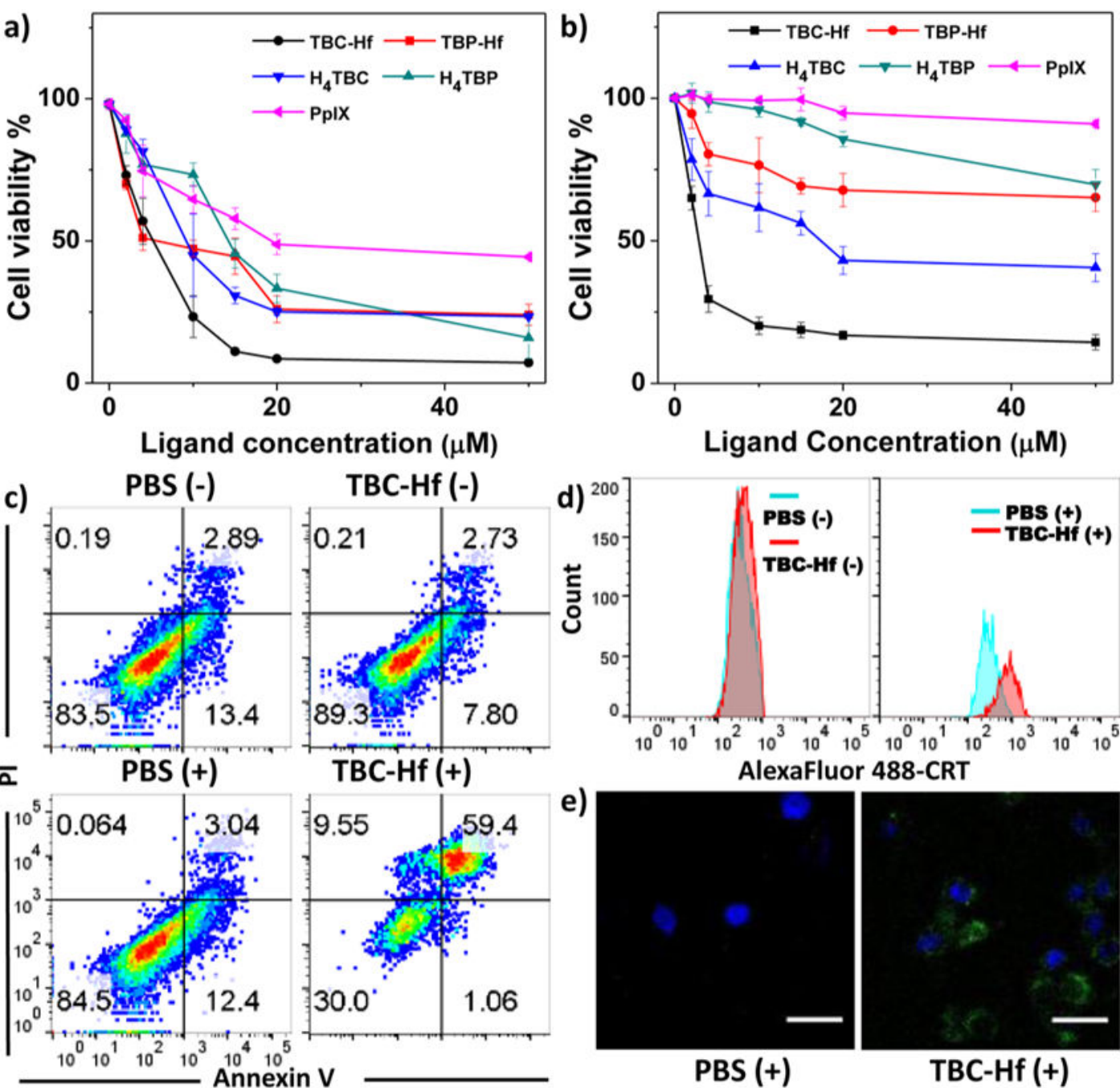

e)

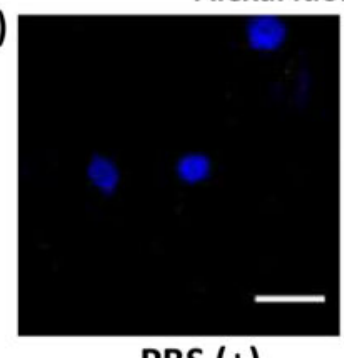

PBS (+)

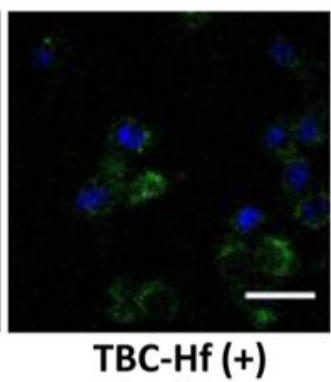

Figure 4.

In vitro $\mathrm{PDT}$ efficacy and mechanistic study. PDT cytotoxicity of $\mathrm{H}_{4} \mathrm{TBP}, \mathrm{TBP}-\mathrm{Hf}, \mathrm{H}_{4} \mathrm{TBC}$,

TBC-Hf, and PpIX at different PS concentrations in CT26 (a) and MC38 cells (b). (c) Annexin V/PI analysis of MC38 cells incubated with TBC-Hf or PBS, with or without irradiation $\left(90 \mathrm{~J} / \mathrm{cm}^{2}\right)$. The quadrants from lower left to upper left (counter clockwise) represent healthy, early apoptotic, late apoptotic, and necrotic cells, respectively. The percentage of cells in each quadrant is shown on each graph. (+) and (-) refer to with and without irradiation, respectively. (d) CRT exposure on the cell surface of MC38 was assessed after incubation with PBS and TBC-Hf, with or without light irradiation $\left(90 \mathrm{~J} / \mathrm{cm}^{2}\right)$, by flow cytometry analysis. The fluorescence intensity was gated on PI-negative cells. (e) Immunofluorescence microscopy of CRT expression on the cell surface of MC38 treated with PBS and TBC-Hf upon irradiation $\left(90 \mathrm{~J} / \mathrm{cm}^{2}\right)$. 

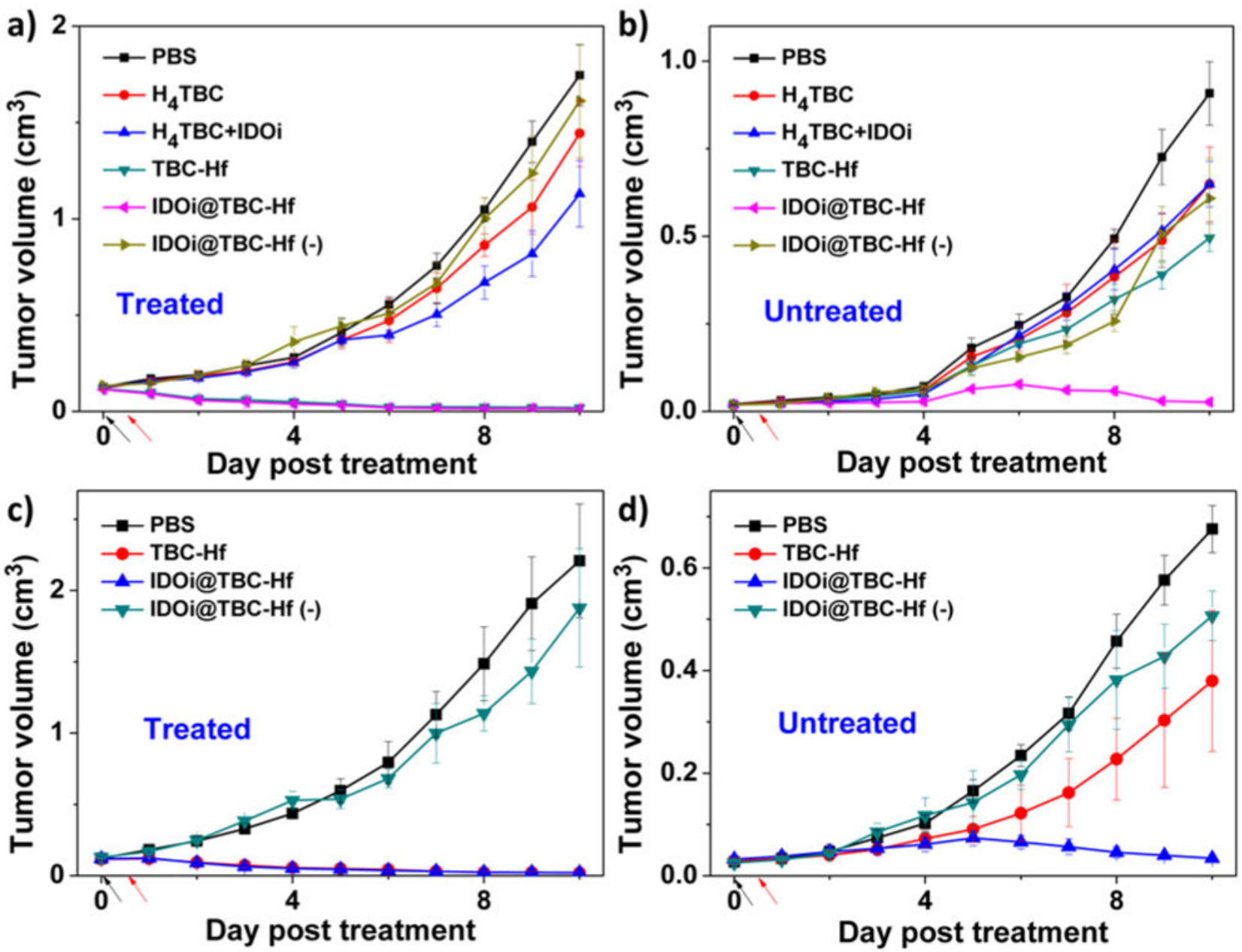

Figure 5.

In vivo anticancer efficacy showing abscopal effect. Growth curves for treated $(\mathrm{a}, \mathrm{c})$ and untreated $(\mathrm{b}, \mathrm{d})$ tumors of CT26 $(\mathrm{a}, \mathrm{b})$ or MC38 $(\mathrm{c}, \mathrm{d})$ tumor-bearing mice after PDT treatment. Black and red arrows refer to the time of injection and irradiation, respectively. 

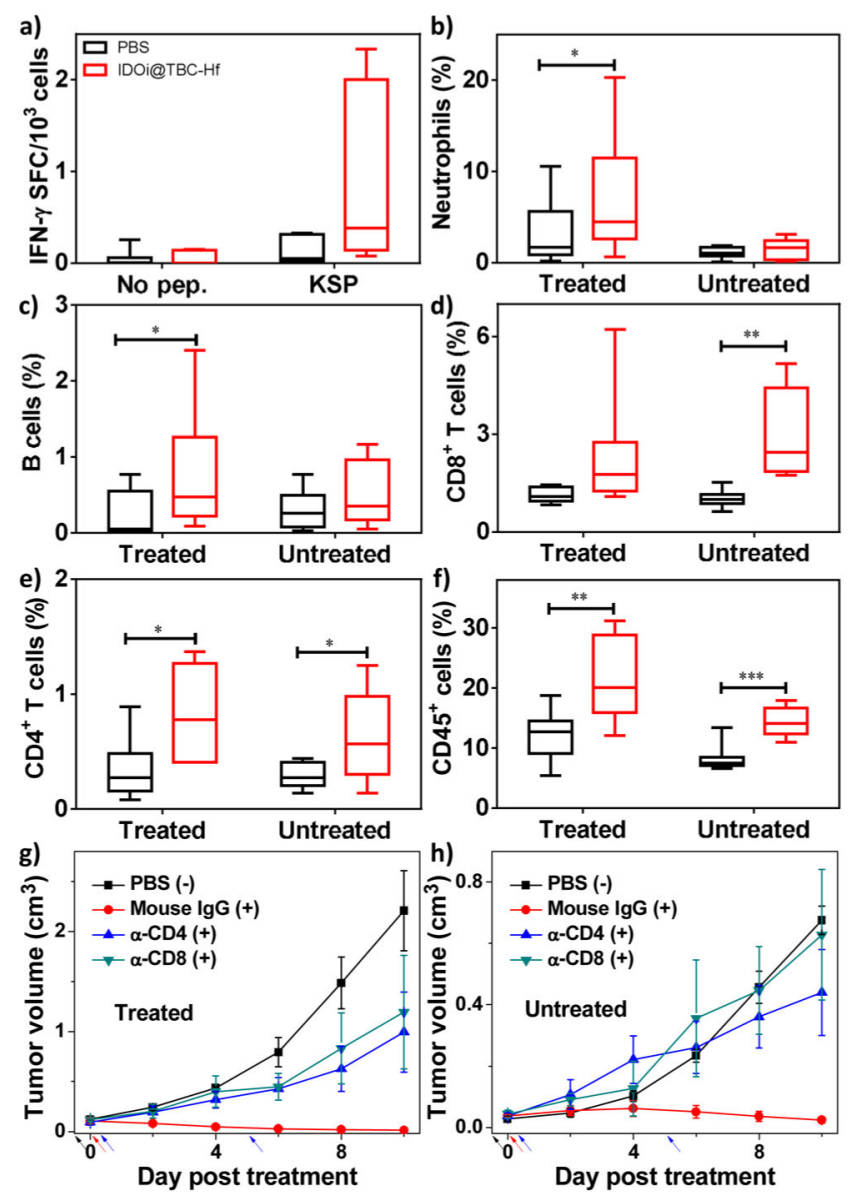

Figure 6.

Antitumor immunity of PDT by IDOi@TBC-Hf. (a) Antigen-specific IFN- $\gamma$ spot forming cells (SFC) 14 days after IDOi@ TBC-Hf PDT treatment. The percentage of tumorinfiltrating neutrophils (b) and B cells (c) with respect to the total number of cells in the tumor compared to PBS, 12h after IDOi@TBC-Hf PDT treatment. The percentage of tumorinfiltrating $\mathrm{CD}^{+} \mathrm{T}$ cells (d), $\mathrm{CD} 4^{+} \mathrm{T}$ cells (e), and $\mathrm{CD}^{+} 5^{+}$cells (f) with respect to the total number of cells in the tumors 12 days after IDOi@TBC-Hf PDT treatment. Growth curves for primary, treated $(\mathrm{g})$ and distant, untreated $(\mathrm{h})$ tumors after PDT treatment $(+)$ with IDOi@TBC-Hf and injections of Mouse IgG, anti-CD4, or anti-CD8 antibody, compared to PBS control without PDT treatment (-). Black, red, and blue arrows refer to the time of IDOi@TBC-Hf injection, light irradiation, and antibody injection, respectively. 


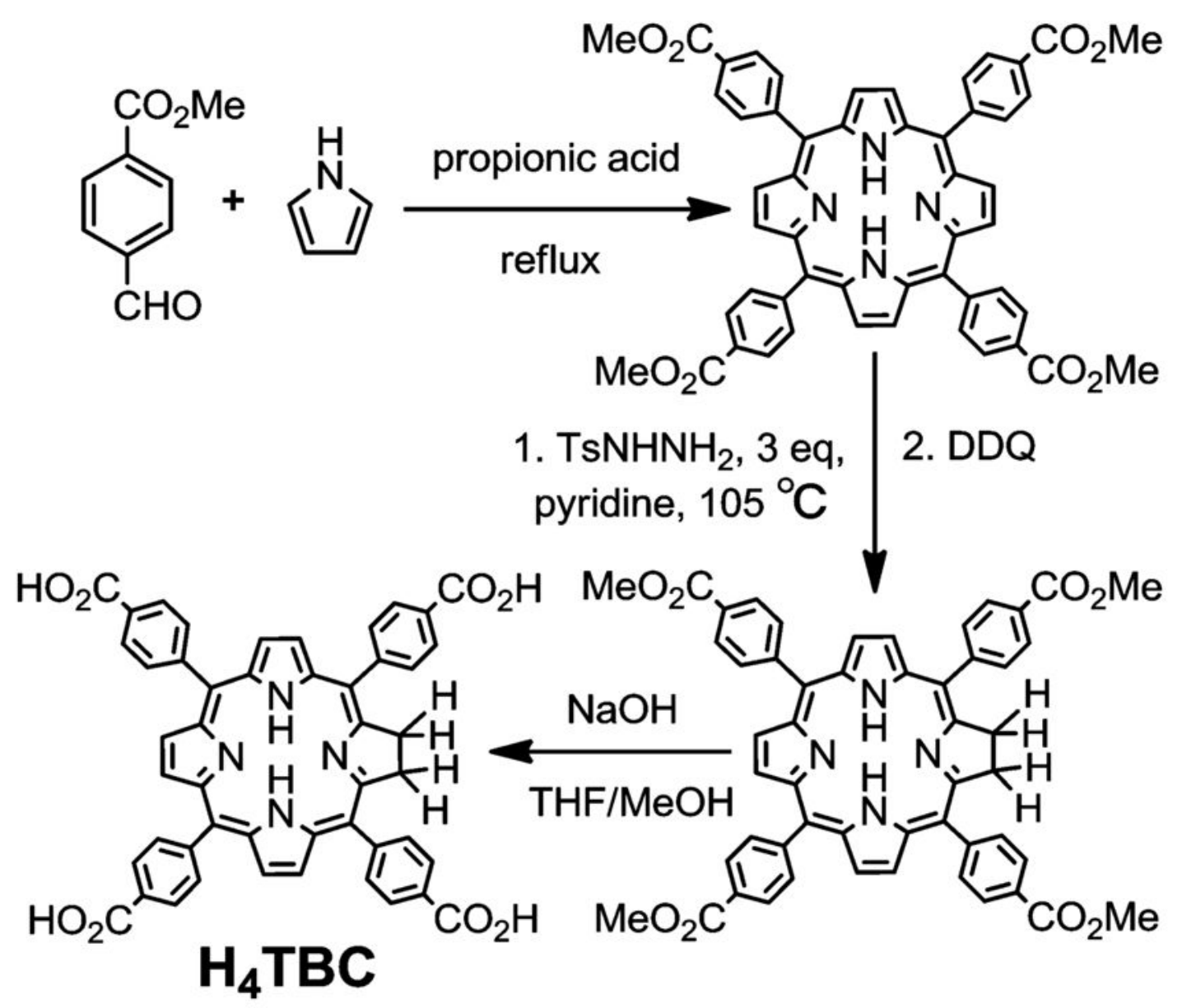

Scheme 1.

Synthesis of 5,10,15,20-Tetra( $p$-benzoato)chlorin $\left(\mathrm{H}_{4} \mathrm{TBC}\right)$ 